\title{
The Use of Medical Apparatus of THz-Therapy "Ka Ve Tche-O2-Orbit” on 129.0 GHz on Molecular Spectrum of Radiation and Absorbation of Atmospheric Oxygen in Healthy Volunteers and in Patients with Involutional Macular Degeneration
}

\author{
Vyacheslav F. Kirichuk* , Larisa E. Fedorischeva, Ksenya U. Eremenko, Anatolya F. Cypyaschuk, \\ Elena V. Ponukalina, Alexander A. Tsymbal, Irina V. Smychlyaeva, Olga N. Antipova, \\ Tatyana S. Velikanova, Elena S. Olenko, Liliana K. Tokaeva, Natalia E. Babichenko
}

Saratov State Medical University Named after V.I. Razumovskiy, Saratov City, Russia.

Email: "normalf@yandex.ru

Received October $5^{\text {th }}, 2013$; revised November $4^{\text {th }}, 2013$; accepted December $2^{\text {nd }}, 2013$

Copyright (C) 2013 Vyacheslav F. Kirichuk et al. This is an open access article distributed under the Creative Commons Attribution License, which permits unrestricted use, distribution, and reproduction in any medium, provided the original work is properly cited. In accordance of the Creative Commons Attribution License all Copyrights (C) 2013 are reserved for SCIRP and the owner of the intellectual property Vyacheslav F. Kirichuk et al. All Copyright (C) 2013 are guarded by law and by SCIRP as a guardian.

\begin{abstract}
The study aims at the influence of THz radiation on $129.0 \mathrm{GHz}$ of atmospheric oxygen on arterial pressure (A/P) and pulse, hemodynamic parameters of orbital arteries during the irradiation of biological active points of application in healthy volunteers and in patients with involutional macular degeneration (IMD). A decrease of systolic and diastolic components of arterial pressure and pulse, and a normalization of systolic velocity of bloodstream (CVB) and of resistance index (RI) in orbital arteries in patients with IMD are noticed. The results of the research are: 1) the method of $\mathrm{THz}$ influence on $129.0 \mathrm{GHz}$ on molecular spectrum of radiation and absorbation of atmospheric oxygen is safe and doesn't cause any negative side effects on common state in healthy volunteers and in patients with IMD; 2) single influence of $\mathrm{THz}$ waves on $129.0 \mathrm{GHz}$ on molecular spectrum of radiation and absorbation of atmospheric oxygen is caused by statistical important improvement in vascular system of eyeball.
\end{abstract}

Keywords: THz Waves; Atmospheric Oxygen; Dopplerography; Orbital Vessels; Maculodystrophy

\section{Introduction}

Pathology of retina macular zone, one of the topical medico-social problems of modern ophthalmology, is the leading reason of the loss of central vision [1].

The incidence of involutional macular degeneration in Russia is 15 on 1000 of population [2,3]. Dystrophic changes in central zone of retina meet in $40 \%-76.5 \%$ and occupy the third place in reasons of significant decrease of vision in people after 50 years [4].

IMD is characterized of non-reversible progressive hitting of central photoactive zone of retina and is one of nosologic forms which very often cause the loss of vision

\footnotetext{
${ }^{*}$ Corresponding author.
}

in population of developed countries [5]. One of etiopathopoiesic factors of chorioretinal changes on eye-ground is disturbance of microcirculation in choroid (in its choroidocapillaceous layer) and in the retina because of vessel obliteration, development of microaneurysms, stasis and trombogenicity in choroidocapillarios bringing to local ischemia [6-8]. An increased vessel permeability of choroidocapillarios layer leading to exudation, oedema and hypoxia of retinal tissue appeared.

Today, there are conservative, laser, surgical and physiotherapy treatments of IMD. The number of patients with physical factors grows every year. It is the attribute with growing effectiveness of physical methods of therapy. Further quest of new noninvasive therapy of dys- 
trophic processes of retina is still topical.

Last year, the process of basic science, medical technician and clinical medicine was determined by achievements in electromagnitobiology, in ka ve tche and $\mathrm{THz}$ technologies $[9,10]$.

Oxygen lack in tissues leads to disturbance of oxidative processes causing hypoxia and ischemia. So, it is very important to study $\mathrm{THz}$ electromagnetic waves on $129.0 \mathrm{GHz}$ of atmospheric oxygen [11]. Last year, THz waves on $129.0 \mathrm{GHz}$ on molecular spectrum of radiation and absorbation of atmospheric oxygen aroused great interest [12-16]. In experiments on animals, there was discovered normalization of coagulation and fibrinolytic blood activity, blood rheology after electromagnetic radiation and absorbtion on $129.0 \mathrm{GHz}$ of atmospheric oxygen [13-17].

It is aimed to study the influence of $\mathrm{THz}$ radiation of 129.0 GHz on molecular spectrum of radiation and absorbation of atmospheric oxygen on common state and hemodynamic parameters of orbital arteries during the irradiation of biological points of application (points of acupuncture) in healthy volunteers and in patients with involutional macular degeneration.

\section{Materials and Methods}

There had been examined 18 practically healthy persons (36 eyes) - the first group and 20 patients (34 eyes) with IMD - the second group. The 1st group consists of persons aged from 25 to 45 years, the 2 nd group-from 50 to 75 years.

Ophthalmic examination included: visometry without and with correction, perimetry, pneumotonometry, biomicroscopy, direct ophthalmoscopy. Also arterial pressure and pulse were examined. Modern additional noninvasive methods included color doppler mapping of central retinal artery (CRA), ophthalmic artery (OphA), rear short ciliary medial and lateral arteries (RSmedCA, RSlatCA) on the apparatus Voluson 730 Pro, GE with the help of sensor SP 6-12. Determined systolic velocity of bloodstream, diastolic velocity of bloodstream and resistance index in the vessels, the examination of orbital vessels was held by lying on the back.

In all persons there was $\mathrm{THz}$ irradiation of the skin in two biological active points (BAP)-VB1, TR23 on 129.0 $\mathrm{GHz}$ of atmospheric oxygen on the uninterrupted regime. The point VB1 is situated on 0.5 цунь (translation from Russian: "zun") from the lateral angle of the eye, in the depression, and TR23 - on the lateral end of the eyebrow. These are the points of the traditional KBЧ-therapy (translation from Russian: "ka ve tche-therapy") [2].

The session was held with the help of medical apparatus of THz-therapy "КВЧ-О2-Орбита" (translation from
Russian: "ka ve tche-O2-Orbita") created by Saratov Central Scientific Institute of Measuring Equipment (Saratov, Russia). The procedure was held sitting in an armchair in a comfortable relax posture.

Each point was irradiated separately, one time, during 5 minutes on each BAP (total 10 minutes). After the irradiation arterial pressure, pulse and bloodstream of orbital arteries were examined once more.

\section{Results}

Persons of the first group had emmetropia. They had no pathology of the eyeground. Visual acuity was $0.9-1.0$.

Patients of the second group had central involutional maculadystrophy in one or both eyes. They had different forms of IMD: "dry" - 13 patients (24 eyes), "wet" - 7 patients (10 eyes). On average incorrective visual acuity was $0.21 \pm 0.03$.

In persons of the first group, arterial pressure and pulse were within physiological norm: systolic $\mathrm{A} / \mathrm{P}$ $112.88 \pm 8.15 \mathrm{mmHg}$, diastolic $\mathrm{A} / \mathrm{P}-73.98 \pm 3.06$ mmHg; pulse- $74.63 \pm 2.05$ beats in minute. In the second group were patients with arterial hypertonia, so they had increased parameters of arterial pressure and pulse: systolic $\mathrm{A} / \mathrm{P}-151.8 \pm 9.47 \mathrm{mmHg}$, diastolic $\mathrm{A} / \mathrm{P}-82.06$ $\pm 2.02 \mathrm{mmHg}$; pulse $-77.8 \pm 2.1$ beats in minute (Table 1).

Medium bloodstream parameters of orbital arteries are in Table 2.

From Table 2, one can see that bloodstream parameters of orbital arteries in the 1st group are within physiological norm. But patients in the 2nd group have decreased indices of CVB in all examined vessels comparing with the 1st group. There are increased indices of RI comparing with norm in all vessels in patients of the 2nd group. These abnormalities show hemodynamic disturbances in the rear segment of eyeball in patients with IMD.

During and after irradiation of points of application with the help of $\mathrm{THz}$ electromagnetic waves on 129.0 $\mathrm{GHz}$ of atmospheric oxygen no one made any complaints on bad common state or discomfort near application place.

In the 1 st and the 2 nd groups, there was reliable decrease of systolic and diastolic components of arterial pressure and pulse frequency. Indices of arterial pressure and pulse in the 1st and the 2 nd groups before and after THz influence are in Table 3.

After THz irradiation of the BAPs on $129.0 \mathrm{GHz}$ of molecular spectrum of radiation and absorbation of atmospheric oxygen trends the decrease in parameters of CVB and RI in all vessels in the first group, even when they are wrong reduction they are within the physiological norm. In patients of the second group, we noticed a 
The Use of Medical Apparatus of THz-Therapy "Ka Ve Tche-O2-Orbit" on 129.0 GHz on Molecular Spectrum of

Radiation and Absorbation of Atmospheric Oxygen in Healthy Volunteers and in Patients with Involutional

Macular Degeneration

Table 1. Indices of arterial pressure and pulse in the first and second groups $(\mathrm{M} \pm \mathbf{m})$.

\begin{tabular}{|c|c|c|}
\hline Group & 1 group $(\mathrm{n}=18$ persons $)$ & 2 group $(\mathrm{n}=20$ patients $)$ \\
\hline Syst. A/P, mmHg & $112.88 \pm 8.15$ & $151.8 \pm 9.47^{* *}$ \\
\hline Diast. $\mathrm{A} / \mathrm{P}, \mathrm{mmHg}$ & $73.98 \pm 3.06$ & $82.06 \pm 2.02^{*}$ \\
\hline Pulse, beats in min & $74.63 \pm 2.05$ & $77.8 \pm 2.1$ \\
\hline
\end{tabular}

Note: data reliable $\mathrm{p}<0.05^{*}, \mathrm{p}<0.01^{* *}$ comparing with the 1 st group.

Table 2. Bloodstream parameters of orbital arteries in healthy persons and in patients with involutional macular degeneration (M $\pm \mathbf{m})$.

\begin{tabular}{ccc}
\hline \multicolumn{1}{c}{ Group } & 1 group $(\mathrm{n}=36$ eyes $)$ & 2 group $(\mathrm{n}=34$ eyes $)$ \\
\hline CVBrameter CRA, cm/s & $16.17 \pm 0.7$ & $13.02 \pm 1.04^{*}$ \\
DVB CRA, cm/s & $3.53 \pm 0.23$ & $3.86 \pm 0.96$ \\
RI CRA & $0.71 \pm 0.04$ & $0.81 \pm 0.03^{*}$ \\
CVBmed RSCA, cm/s & $14.47 \pm 1.05$ & $10.86 \pm 1.06^{*}$ \\
DVBmed RSCA, cm/s & $5.05 \pm 0.42$ & $3.77 \pm 0.31^{*}$ \\
RI med RSCA & $0.61 \pm 0.06$ & $0.75 \pm 0.03^{*}$ \\
CVB lat RSCA, cm/s & $14.85 \pm 0.9$ & $10.53 \pm 0.87^{*}$ \\
DVB lat RSCA, cm/s & $5.01 \pm 0.36$ & $3.42 \pm 0.64^{*}$ \\
RI lat RSCA & $0.63 \pm 0.05$ & $0.74 \pm 0.02^{*}$ \\
CVB OphA, cm/s & $31.45 \pm 1.01$ & $27.56 \pm 1.15^{*}$ \\
DVB OphA, cm/s & $8.31 \pm 0.65$ & $11.07 \pm 1.06^{*}$ \\
RI OphA & $0.77 \pm 0.02$ & $0.87 \pm 0.04^{*}$ \\
\hline
\end{tabular}

Note: data reliable $\mathrm{p}<0.05^{*}$ comparing with the 1 st group.

Table 3. Indices of arterial pressure and pulse in the 1st and the 2nd groups before and after THz influence on the BAPs (M \pm m).

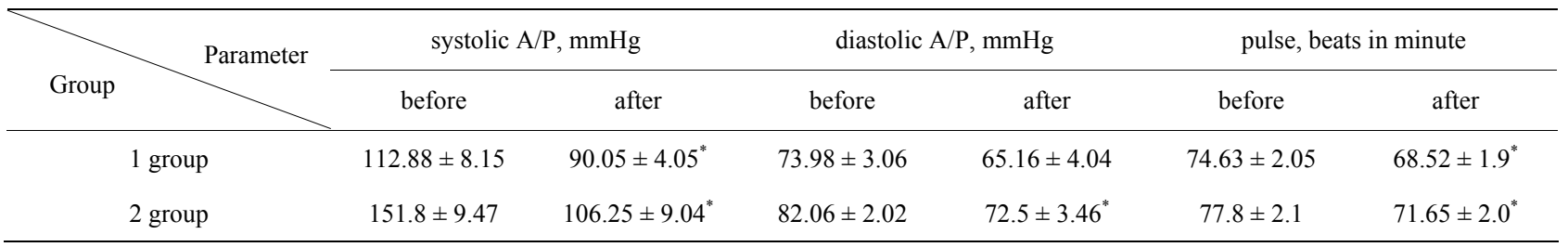

Note: data reliable $\mathrm{p}<0.05^{*}$.

significant decrease of CVB in central retinal artery and it was increased in rear short ciliary lateral and ophthalmic arteries, RI was significantly reduced in these vessels (Table 4).

\section{Conclusions}

1) The observation shows safety of the THz-waves influence on $129.0 \mathrm{GHz}$ of atmospheric oxygen because it doesn't cause any negative side effects on common state in healthy volunteers and in patients with IMD.

2) Short single $\mathrm{THz}$ influence on $129.0 \mathrm{GHz}$ of atmospheric oxygen held to statistic important improvement in vascular system of eyeball. So, the research will be continued. This method can be used for treatment of patients with different vascular eye pathologies.

3) There are first clinical results of $\mathrm{THz}$ influence on 129.0 GHz of atmospheric oxygen on eye hemodynamic 
Table 4. Bloodstream parameters of orbital arteries before and after THz influence on $129.0 \mathrm{GHz}$ of atmospheric oxygen (M $\pm \mathbf{m})$.

\begin{tabular}{ccccc}
\hline \multirow{2}{*}{ Parameter } & \multirow{2}{*}{ Group } & \multicolumn{2}{c}{1 group $(\mathrm{n}=36$ eyes $)$} & \multicolumn{2}{c}{2 group $(\mathrm{n}=34$ eyes $)$} \\
\cline { 2 - 5 } & before & after & before & after \\
\hline CVB CRA, cm/s & $16.17 \pm 0.7$ & $13.96 \pm 0.8^{*}$ & $13.02 \pm 1.04$ & $10.13 \pm 0.91^{*}$ \\
DVB CRA, cm/s & $3.53 \pm 0.23$ & $4.46 \pm 0.27^{*}$ & $3.86 \pm 0.96$ & $3.20 \pm 0.27$ \\
RI CRA & $0.71 \pm 0.04$ & $0.60 \pm 0.03^{*}$ & $0.81 \pm 0.03$ & $0.68 \pm 0.05^{*}$ \\
CVBmed RSCA, cm/s & $14.47 \pm 1.05$ & $12.20 \pm 1.04$ & $10.86 \pm 1.06$ & $11.76 \pm 1.04$ \\
DVBmed RSCA, cm/s & $5.05 \pm 0.42$ & $4.84 \pm 0.34$ & $3.77 \pm 0.31$ & $4.25 \pm 0.38$ \\
RI med RSCA & $0.61 \pm 0.06$ & $0.60 \pm 0.06$ & $0.75 \pm 0.03$ & $0.64 \pm 0.05$ \\
CVB lat RSCA, cm/s & $14.85 \pm 0.9$ & $12.20 \pm 0.91^{*}$ & $10.53 \pm 0.87$ & $12.98 \pm 0.83^{*}$ \\
DVB lat RSCA, cm/s & $5.01 \pm 0.36$ & $5.53 \pm 0.22$ & $3.42 \pm 0.64$ & $4.95 \pm 0.35^{*}$ \\
RI lat RSCA & $0.63 \pm 0.05$ & $0.52 \pm 0.02^{*}$ & $0.74 \pm 0.02$ & $0.61 \pm 0.06^{*}$ \\
CVB OphA, cm/s & $31.45 \pm 1.01$ & $30.67 \pm 1.03$ & $27.56 \pm 1.15$ & $33.53 \pm 1.34^{*}$ \\
DVB OphA, cm/s & $8.31 \pm 0.65$ & $8.19 \pm 0.68$ & $11.07 \pm 1.06$ & $8.08 \pm 1.01^{*}$ \\
RI OphA & $0.77 \pm 0.02$ & $0.72 \pm 0.03$ & $0.87 \pm 0.04$ & $0.75 \pm 0.04^{*}$ \\
\hline
\end{tabular}

Note: data reliable $\mathrm{p}<0.05^{*}$.

in healthy people and in patients with macular degeneration.

\section{REFERENCES}

[1] E. P. Kantargy, I. A. Listipadov and M. G. Rabadanova, "Comprehensive Assessment of the Efficiency and the Safety of Lutein-Vitamin Complex in Treatment of Patients with Pathology of Retina and Optic Nerve," Clinical Ophthalmology, Vol. 11, No. 2, 2010, pp. 40-44.

[2] U. S. Astahov, A. B. Lisichkina and F. E. Shadrichev, "Involutional Macular Degeneration. Clinical Recommendations," In: L. K. Moschetova, A. P. Nestsrov and E. A. Egorov, Eds., Ophthalmology, GEO-TAR-Media, 2006, pp. 164-188.

[3] E. S. Libman, R. A. Tolmachev and E. V. Shahova, "Epidemiological Characteristics of Disability Due to the Main Forms of Maculopathy," In: U. A. Ivanishko, Ed., Proceedings of the II-d all-Russian Seminar "Macula", "Round Table Conference", Rostov-on-Don, 2006, pp. $15-22$.

[4] L. A. Kancelson, T. I. Forofonova and A. Ya. Bunin, "Vascular Diseases of the Eye," Medicine, 1990, 272 p.

[5] M. V. Budzinsky, M. V. Vorobeva, T. N. Kiseleva, U. M. Lagutina and G. S. Polunina, "Modern Approaches to Treatment and Prevention to Involutional Macular Degeneration," Clinical Ophthalmology, Vol. 8, No. 2, 2007 , pp. 78-82.

[6] G. P. Smolyakova and V. S. Lisenko, "Pathogenic Approaches to the Treatment of Involutional CHRD," Methodic recommendations, Khabarovsk, 1988, $35 \mathrm{p}$.

[7] A. L. Korzweig, "The Eye in Old Age," American Jour- nal of Ophthalmology, Vol. 60, No. 5, 1965, pp. 835-843.

[8] P. D. Syeinbuch, "Under die Beteigung der WetzhautKapillararen bei der Senile Macula Degeneration," Klin. Mbl. Augenheilk, Vol. 156, No. 5, 1970, pp. 710-715.

[9] O. V. Becki, A. P. Krenickii, A. V. Maiborodin, et al., "Biophysical Effects of THz Waves and Future Prospects of New Directions in Biomedical Technology: 'THz-Therapy' and 'Thz-Diagnostics'," Biomedical Technologies and Radioelectronics, Vol. 12, 2003, pp. 3-6.

[10] V. F. Kirichuk, T. V. Golovacheva and A. G. Chisch, "Ka-Ve-Tche-Therapy," Publisher of SarSMU, Saratov, 1999, $272 \mathrm{p}$

[11] A. A. Tsymbal, "The Method of Recovery of Fibrinolytic Activity of Blood during THz-Radiation on $129.0 \mathrm{GHz}$," Scientific Creativity XXI Century: Proceedings of the 2nd All-Russian Scientific Conference with International Engagement, Krasnoyarsk, 2010, p. 122.

[12] O. V. Becki, A. S. Kozmin and U. G. Yaremenko, "Possible Applications of Thz Waves," Biomedical Radioelectronics, Vol. 3, 2008, pp. 48-54.

[13] V. F. Kirichuk, A. N. Ivanov, A. A. Tsymbal, et al., "Application of THz-Therapy in Clinical Practice (under edition of V. F. Kirichuk, A. P. Krenickii)," Saratov, 2011, $135 \mathrm{p}$.

[14] V. F. Kirichuk, A. A. Tsymbaland A. P. Krenickii, “Application of THz Radiation of Atmospheric Oxygen 129.0 $\mathrm{GHz}$ for Correction of Hemocoagulation and Fibrinolytic Disorders," Biomedical Radioelectronics, Vol. 9, 2009, pp. 11-16.

[15] V. F. Kirichuk, O. N. Antipova, A. N. Ivanov, et al., "Influence of Different Radiation Regimes of THz-Waves on Regeneration of Rheological Properties of Blood in White 
The Use of Medical Apparatus of THz-Therapy "Ka Ve Tche-O2-Orbit” on 129.0 GHz on Molecular Spectrum of Radiation and Absorbation of Atmospheric Oxygen in Healthy Volunteers and in Patients with Involutional

Macular Degeneration

Rats during Stress-Reaction," Millimiter Waves in Biology and Medicine: Proceedings of 14th Russian Symposium with International Engagement, 2007, pp. 148-151.

[16] V. F. Kirichuk, S. V. Suhova, O. N. Antipova, et al., "Influence of EMR THzF on Molecular Spectrum of Radiation and Absorbation of Oxygen on Functional Activity of Platelets in White Rats during Immobilization Stress,"
Biomedical Radioelectronics, Vol. 12, 2008, pp. 41-48.

[17] A. A. Tsymbal, "Regularities of Biological Action of Electromagnetic $\mathrm{THz}$-Waves on Frequencies of Active Cellular Metabolites on Poststress Hemostasis Changes: Abstract dis $\cdots$ doct. med. Sciences," A. A. Tsymbal, Saratov, 2012, 50 p. 